\title{
Pensando Além da Homonormatividade: Explorações Performativas de Economias Gays Diversificadas $^{1}$
}

\author{
Thinking Beyond Homonormativity: Performative Explorations of Diverse Gay \\ Economies
}

\author{
Gavin Brown \\ University of Leicester - United Kingdom \\ gpb10@le.ac.uk
}

\begin{abstract}
Resumo
Este artigo performativamente descentra o papel do consumo gay nas correntes do pensamento contemporâneo sobre a vida econômica e social de lésbicas e gays no Norte Global. É ao mesmo tempo crítico e reparador nessa perspectiva. Este trabalho engaja-se criticamente com as obras da década passada sobre a homonormatividade, sugerindo que estes trabalhos apresentam a 'homonormatividade' como uma estrutura por demais abrangente e que se torna politicamente incontestável. Em paralelo com a análise contemporânea de como as vidas lésbicas e gays se tornam cúmplices na reprodução de diversas normatividades, este artigo assume a posição inovadora e reparadora de se considerar como tais espaços e práticas também produzem relações interdependentes entre diferenças sociais. Com base na obra de Julie Graham e Katherine Gibson, publicada em 2006, 'A Postcapitalist Politics', este artigo considera tais perspectivas para delinear a diversidade de práticas econômicas de lésbicas e gays, com a ambição performativa de fazer práticas não capitalistas existentes mais visíveis e viáveis. Para este fim, o artigo examina um número de espaços e práticas gays para analisar os diferentes formatos de empreendimentos, transações e trabalho que ocorrem dentro destas. Com base em um inventário preliminar das diversas práticas econômicas e espaços gays, este trabalho propõe que já existem muitos aspectos da vida gay urbana e contemporânea que já oferecem alternativas às práticas homonormativas do neoliberalismo
\end{abstract}

Palavras - chave: Homonormatividade; Economia; Gay.

\begin{abstract}
This paper performatively decentres the role of mainstream gay consumption in contemporary thought about the economic and social lives of lesbians and gay men in the Global North. It is simultaneously critical and reparative in outlook. This paper critically engages with writing on homonormativity from the last decade, suggesting that this work presents 'homonormativity' as an all-encompassing structure that becomes politically unassailable. In parallel with an analysis of contemporary lesbian and gay life as being complicit in the reproduction of various normativities, this paper takes the innovative and reparative stance of considering how such spaces and practices also produce interdependent relationships across social difference. Drawing on the work of Gibson-Graham (2006, 'A Postcapitalist Politics', University of Minnesota Press, Minneapolis, MN) this paper considers the prospects for outlining the diversity of lesbian and gay economic practices, with the performative ambition of making existing noncapitalist practices more visible and viable. To this end, the paper examines a number of gay spaces and practices to consider the different forms of enterprise, transactions, and labour that take place within them. On the basis of its preliminary inventory of diverse gay economic practices and spaces, this paper proposes that there are many aspects of contemporary urban gay life that already offer alternatives to the homonormative practices of neoliberalism.
\end{abstract}

Keywords: Homonormativity; Economy; Gay. 


\section{Introdução}

Desde que geógrafos da sexualidade engajaram-se com a teoria queer, eles tem analisado espaços e práticas espaciais que mantêm a 'heteronormatividade', o processo que constrói socialmente privilégios à heterossexualidade, e o correlato entendimento binário de gênero, sobre a homossexualidade e apresentações de gênero não convencionais (BELL et al, 1994; BROWNE et al, 2007; HUBBARD, 2008). Na última década, geógrafos e outros teóricos (CASEY, 2007; HARITAWORN, 2007; OSWIN, 2005; SOTHERN, 2007) têm, de diversos modos, começado a usar e ocasionalmente questionar, o conceito de 'homonormatividade' (DUGGAN, 2002; NAST, 2002; PUAR, 2006) para descrever e criticar os meios pelos quais algumas formas de homossexualidade 'assimiladas' se tornaram elas mesmas normativas e incorporadas dentro da lógica da heteronormatividade. Tal processo de mudança social, legal e política, referido como 'liberalismo queer' (ENG et al, 2005), reforça o entendimento da homonormatividade como 'a política sexual do Neoliberalismo' (DUGGAN, 2002).

Desde o começo dos anos 90 houve indubitavelmente uma mudança, ainda que incompleta e parcial, em atitudes sociais e culturais quanto às principais expressões de homossexualidade nos países do Norte Global e, cada vez mais, em outras partes. Essas mudanças de atitudes são expressas em diversas áreas da vida social, desde a representação pela mídia do estilo de vida gay, até novas formas de cidadania sexual para gays e lésbicas (equiparação da idade do consentimento, repúdio de legislações discriminatórias e a extensão do casamento e união civil aos casais do mesmo sexo) (BELL \& BINNIE, 2000). O escopo dessas mudanças é captado por Weeks (2007, p. 2-3) em seu livro bastante otimista The World We Have Won:

O que parecia impensável trinta anos atrás, impossível há vinte, improvável há dez, (pelo menos na Inglaterra conhecida por sua letargia) é agora corrente. Somente com a vociferação dos religiosos evangélicos e as piadas ocasionais sobre quem lava a louça e usa as calças, para nos lembrar de uma época anterior onde o casamento heterossexual era a única forma sancionada de sexualidade e respeitabilidade e onde os homossexuais eram 'os homens mais perniciosos da Inglaterra' (ênfase no original).
Eu não contesto que essas mudanças ocorreram, nem que elas tiveram um impacto positivo nas vidas cotidianas de muitos gays e lésbicas. Ao mesmo tempo, eu compartilho muitas das apreensões dos teóricos que criticaram as consequências dessas mudanças por terem recentrado as vidas de privilegiados homens brancos gays (HARITAWORN, 2007; NAST, 2002; PUAR, 2007), reforçando normativamente o casal amoroso, e marginalizando ainda mais aqueles que levam estilos de vidas mais queer (incluindo gênero queer). Entretanto, tenho me tornado cada vez mais apreensivo de que há o risco de que quanto mais nós nomearmos de 'homonormatividade' e (a)criticamente a aplicarmos à todas as expressões aceitas da cultura lésbica e gay, mais aumentamos seu poder discursivo e a reforçamos como dominante, incontestável expressão do (um tanto onipotente quanto onipresente) neoliberalismo na esfera da vida privada ${ }^{2}$. Parece-me que o projeto queer oferecia uma promessa diferente:

O projeto [queer] pode ser visto a não (ou não somente) incorporar a constituição de uma população minoritária calcada no desejo pelo mesmo sexo, configurada em oposição à norma heterossexual, mas sim, por contestar a própria noção de normas e de normalidade, chamando atenção para a violência atrelada à normalização do impulso, incluindo o impulso a teorizar o lócus social como subsumido na ordem hegemônica (GIBSON-GRAHAM, 1999, p. 83).

Críticos da homonormatividade indubitavelmente acreditam estar oferecendo uma crítica radical da normalização dos impulsos de uma política sexual reconfigurada. Porém, eu questiono o que acontece quando aquele crítico queer das tendências normalizadoras acaba performaticamente (re)constituindo aquelas tendências como particularmente unidimensionais e hegemônicas. Será que essas representações fortalecem o poder da 'homonormatividade', fazendo-a parecer menos permeável a contestação, desencorajando potenciais intervenções políticas e contestações exitosas?

Não obstante os escritores mais críticos à homonormatividade a situem como uma expressão das amplas práticas políticas e econômicas do neoliberalismo, nenhum deles considerou ainda as práticas econômicas através das quais relações sociais homonormativas são produzidas e expandidas. Ao invés de oferecer um inventário de práticas econômicas 'homonormativas' internas ao

\section{Gavin Brown}


neoliberalismo, eu busco pensar através da diversidade de práticas econômicas gays (pelas quais valores de uso são produzidos, consumidos e permutados) de um modo mais performativo - nomeando aquelas práticas tornadas 'invisíveis' pelo vínculo discursivo entre homonormatividade e neoliberalismo. Ao fazer isso, sou inspirado pela leitura queer da globalização e capitalismo oferecida por Gibson-Graham (1996; 1999) e a sua tentativa de tornar visível "a grande variedade de práticas [marginalizadas] não capitalistas" (GIBSON-GRAHAM, 2006, p. XXXII), visando "contribuir para políticas anticapitalistas de invenção econômica” (GIBSON-GRAHAM,1996, p. $\mathrm{XI})$.

Isso envolve não somente um ato de substituir 'homonormatividade' por 'capitalismo' na manobra queer de Gibson-Grahan, mas o reconhecimento de como as discussões sobre homonormatividade estão ligadas às pressuposições sobre a dominação de formas neoliberais do capitalismo e a saturação da vida gay por elas. Eu estou interessado em voltar à atenção das manobras queers novamente para representações de espaço gay e vidas gays. Prosseguindo nessa abordagem, eu espero descentrar a dominância das expressões homonormativas do neoliberalismo dos debates sobre o papel de práticas econômicas nas vidas gays. Como Gibson-Graham (1996, p. 144-145), eu questiono: 'que poder e potencialidades nós renunciamos quando aceitamos a univocidade do mercado/mercadoria/totalidade global capitalista?'

$\mathrm{Eu}$ também temo que, se os geógrafos das sexualidades continuarem a pensar na homonormatividade como uniforme e abrangente, corremos o risco de perder qualquer sentido da especificidade geográfica destas mudanças sociais, políticas e econômicas e vamos desconsiderar como esses processos e práticas são vivenciados de forma desigual e de maneiras muito diversas, dependendo de seu contexto espacial (BROWN, 2008; VISSER, 2008). Isso negaria a possibilidade de um engajamento geograficamente nuançado com vidas queer, tanto no Norte Global, quanto no Sul Global. Há duas maneiras diferentes de fazer a leitura do panorama da vida gay contemporânea: uma leitura para a hegemonia, a outra para a diferença, diversidade e especificidade geográfica. Essas duas leituras têm diferentes efeitos performativos. Eu fiz a escolha ética pela leitura da diferença.

O corpo principal deste trabalho começa com uma breve revisão crítica dos trabalhos escritos sobre a homonormatividade por geógrafos e outros cientistas sociais. Além de identificar os trabalhos fundamentais que propuseram e articularam o vínculo entre práticas homonormativas e o neoliberalismo contemporâneo, esta seção também se engaja com trabalhos que tentaram procurar meios de dissolver oposições binárias simplistas entre espaço gay homonormativo e espaço queer 'autêntico', 'transgressor', reconhecendo a cumplicidade de todos esses locais em reproduzir várias crenças e práticas normativas. Tendo aferido esses debates, eu abordo com algum pormenor o trabalho de Gibson-Graham e outros que teorizaram como o conceito de práticas econômicas diversas pode ser implementado performativamente como um modo de reparação. Por trás dessa discussão, eu especulo como teorizações sobre economias diversas poderiam ajudar a repensar a vida econômica de lésbicas e gays urbanos no Norte Global, descentrando o papel de locais tradicionais do consumo gay e fazendo o (estereotipado) consumidor gay, branco, abastado (BADGETT, 2001; CHASIN, 2000; NAST, 2002) diferente de si mesmo no processo. Concluo o artigo considerando como essa linha de pensamento poderia ser usada tanto como meio expansão das possibilidades de modos de vida gay além do, ou em paralelo ao, capitalismo (como o conhecemos), quanto como forma de se estudar a vida de gays e lésbicas em diversos locais, sem julgá-los sempre com os parâmetros dos centros metropolitanos da vida gay que amplamente dominaram as geografias sexuais até hoje (BROWN, 2008).

\section{Análise dos trabalhos escritos sobre 'Homonormatividade'}

Duggan (2002, p. 179) é a responsável por iniciar o debate sobre "a nova homonormatividade", como a política sexual do neoliberalismo quando ela descreveu:

uma política que não contesta os pressupostos heteronormativos dominantes nem instituições mas os sustenta e apóia enquanto promete a possibilidade de um eleitorado gay desmobilizado e privatizado, uma cultura gay despolitizada, ancorada em domesticidade e consumo.

Muitos pesquisadores reconhecem que, na América do Norte, Europa Ocidental, Austrália, Nova Zelândia e África do Sul, a última década testemunhou um número de mudanças de amplo alcance nas circunstâncias legais, econômicas e sociais de muitos gays e lésbicas, e que essas mudanças são uma consequência da extensa gama de práticas econômicas e políticas conhecidas como 'neoliberalismo'. Embora esses processos sejam irregulares, incompletos e muitas vezes contraditórios, eles tenderam a resultar

Gavin Brown 
em uma situação na qual "(alguns) gays e lésbicas constituem cidadãos dignos de inclusão" (RICHARDSON, 2005 p. 521), ao contrário de sua localização social anterior como pessoas que eram percebidas como tendo um escasso valor positivo para oferecer à sociedade.

Por trás do desenvolvimento específico das políticas e práticas 'homonormativas', há o imperativo neoliberal para a privatização dos serviços públicos por empresas com fins lucrativos para promover tanto a expansão econômica quanto a redução da provisão estatal. Isso tem sido associado à promoção ideológica dos direitos (econômicos) individuais e liberdades que são contrapostas às práticas de intervenção estatal. Diferentes regimes de intervenção do Estado resultaram em discrepantes expressões de homonormatividade nos EUA em comparação com países com Estados de bem estar social estabelecidos.

A literatura recente sobre a política sexual do neoliberalismo identifica vários conjuntos (vinculados) de discursos e práticas econômicos, políticos e culturais que mudaram neste período. Primeiro, a linguagem da política gay foi reconfigurada das aspirações de liberdade sexual para reivindicações de cidadania plena e igualitária. Desta forma, "'igualdade' se limita ao acesso formal à algumas instituições conservadoras" (DUGGAN, 2002, p. 190). Da mesma forma, campanhas políticas gays prévias para o direito a privacidade, se tornaram mobilizadas em apoio de um estado miniaturizado e de uma vida pública comprimida.

Como consequência, a vida pública gay e "a diversidade democrática da proliferação de formas de dissidência sexual" (DUGGAN, 2002, p. 190) estão cada vez mais julgados em comparação a uma forma privilegiada de vida gay que tenta replicar aspectos apoiados pelo Estado da primazia heterossexual e prestígio situado no lar e em práticas de consumo relacionados. Nestas circunstâncias, tem-se argumentado que a introdução do casamento de gays e lésbicas, ou outras formas de reconhecimento civil, tornou-se um meio de não só privatizar as aspirações culturais gays, mas também da transferência do fardo da assistência social para a esfera doméstica (DUGGAN, 2002, p. 188; RICHARDSON, 2005, p. 522).

Em outros termos, como Richardson (2005, p. 524) articulou, gays e lésbicas podem ser apresentados como já não preocupantes para a sociedade, pelo menos enquanto as pessoas gays seguirem estas novas regras. Como alguns homens e mulheres gays se tornaram "visivelmente aceitáveis" (RICHARDSON, 2005, p. 524), outros se tornam ainda mais marginalizados (PUAR, 2007). Por dependerem tanto do vocabulário conceitual da política neoliberal, Richardson (2005, p. 517) afirma que o movimento contemporâneo de gays e lésbicas obscurece os impactos negativos e contraditórios das políticas neoliberais sobre muitos gays e lésbicas.

Enquanto as atitudes sociais e políticas frente gays e lésbicas tornaram-se mais tolerantes, proliferou a presença de pessoas gays na mídia hegemônica e um número crescente de grandes corporações lançaram no mercado produtos e serviços dirigidos aos consumidores gays e lésbicas. Nast (2002, p. 880) argumenta que essas imagens da mídia frequentemente estão longe de apresentar "retratos realistas de um amplo espectro da vida gay". Para ela, alguns homens homossexuais (em particular) têm sido 'colonizados' pelo mercado, já que o mundo corporativo reconhece seu potencial como "investidores e consumidores" (2002, p. 880).

Contrastando com as teorizações de Duggan e Richardson, Nast situou sobremaneira essas mudanças sociais e econômicas no interior dos privilégios racistas, patriarcais da "normatividade gay da masculinidade dos homens brancos" (2002, p. 878). Seu trabalho tem sido bastante criticado por ter colapsado a experiência real vivida pela maioria dos homens brancos gays (nos EUA) em um estereótipo do consumidor gay, branco e abastado (ELDER, 2002; SOTHERN, 2004). Para Sothern (2004, p. 187), Nast apresenta uma noção "muito pouco queer de [uma] masculinidade queer" moldada de maneira uniforme pelo neoliberalismo e "desprovida de qualquer multiplicidade, performatividade e contradições que a teoria queer lutou para teorizar".

Oswin $(2005$, p. 84) argumenta que tanto Nast como Sothern se valem de estereótipos de modo a encontrar meios de combater as normalizações neoliberais da vida gay "insistindo que deve haver uma política queer sem cumplicidade" com esses regimes. Ela advoga "uma abordagem mais ambivalente das geografias queer da normalização" (2005, p. 81), persuadindo a deixar a figura do "cúmplice queer", que está sempre envolvido de alguma forma em práticas e relações neoliberais. Se essas práticas neoliberais de normalização constituem uma ameaça para as longamente ensaiadas intervenções teóricas dos estudos queer, então, a busca de um "autêntico, não cúmplice queer" pode atrair como um meio de evitar com que façamos perguntas difíceis e embaraçosas sobre o potencial de políticas queer radicais. Em contraste, Oswin (2005, p. 84) sugere que:

ao invés de pensar em espaço cúmplice como total e negativo, podemos reconceituá-lo como ambivalente e poroso,

\section{Gavin Brown}


como um conjunto indeterminado de processos que, simultaneamente, permitem a resistência e a capitulação. Se tanto a resistência quanto a capitulação estão habilitados na e através da cumplicidade, então, a cumplicidade queer pode assim representar uma ameaça. Porém não é a ameaça que pensamos que fosse, talvez tenhamos que olhar com mais atenção e em lugares inesperados para detectá-la, e podemos nem sempre gostar do que vamos encontrar

O conceito de Oswin $(2005 ; 2007 ; 2008)$ de espaço queer cúmplice serve como um oportuno lembrete de que o espaço de gays e lésbicas pode produzir e reforçar diferentes normatividades (não apenas em torno da sexualidade, mas através das intersecções entre sexualidade, classe, gênero, etnia e nação). Ela nos lembra de que a crítica queer nem sempre se preocupou somente com a reprodução de normatividades, mas com a contestação pósestruturalista às identidades políticas e ao pensamento binário. Espaço Gay não é inerentemente mais resistente ou transgressor que o espaço heterossexual; e, consequentemente, geógrafos queer devem reconhecer que se há muitas heterossexualidades (HUBBARD, 2007), então é um desvario situar espaço heterossexual sempre como opressor e restritivo às vidas de lésbicas, gays e outros 'dissidentes' sexuais e de gênero. $O$ verdadeiro potencial do pensamento queer é o de minar concepções binárias de sexualidade e gênero ao invés de reforçá-las.

Embora eu reconheça que através da mobilização do termo 'cumplicidade' Oswin (2005) está tentando destacar como o espaço lésbico e gay está implicado na reprodução de diferentes normatividades (incluindo heteronormatividade), eu quero sugerir que também pode ser produtivo pensar sobre as relações cotidianas entre modos de vida gay, lésbico e heterossexual em termos de 'interdependência'. Se cumplicidade nos lembra de que mesmo esses locais e práticas que parecem ser 'transgressores' podem reforçar valores normativos então eu sugiro que também há algum valor em repensar como esses locais e práticas que superficialmente parecem reforçar essas normas (ou indicar um estado de 'assimilação') também podem produzir relações sociais inesperadas. Se 'cumplicidade' implica em ser cúmplice de um ato delinquente então "interdependência transmite o sentido de depender e ser responsável pelos outros" (SMITH et al, 2007, p. 340, ênfase no original). O termo reconhece que "todo indivíduo, todo lugar, toda comunidade surgiu por meio de relações de troca entre outras pessoas, lugares ou comunidades" (SMITH et al, 2007, p. 350).

Interdependência não é um estado preexistente do ser, mas um estado de tornar-se o que demanda que a atenção se volte para "os processos ou eventos onde novas conexões e formas de obrigação virão a existir" (SMITH et al, 2007, p. 350). Isso não é para rejeitar noções de cumplicidade, nem de constituir um novo binário entre cumplicidade e interdependência, mas sugerir que, ao limitar a nossa paleta crítica a um constructo em detrimento dos outros, corremos o risco de predeterminar em que resultará nossas pesquisas. Ao mobilizar aqui o termo 'interdependência', eu estou tentando praticar um modo mais reparador de teorizar, que gere esperança e cuidado, juntamente com a crítica queer (LIM, 2007).

No restante deste artigo, eu quero ponderar um meio pelo qual os estudiosos queer possam explorar a porosidade do espaço gay cúmplice e interdependente e identificar espaços e práticas gays que são menos centralmente inscritos na manutenção neoliberal de fluxos econômicos, através dos quais as possibilidades de formas alternativas de vida queer possam ser expandidas e as lacunas contraditórias exploradas. Ao fazer isso, aproximo-me do trabalho de GibsonGraham (2006), no qual elas elaboram a diversidade de práticas e relações econômicas existentes além daquelas associadas ao capitalismo.

\section{Economias diversas}

Ao expandir o vocabulário dos processos econômicos, Gibson-Graham almejam desenvolver uma 'teoria fraca' (SEDGWICK, 2003) das economias (que se recusa a conhecer muito ou estender muito longe suas análises), em contraste com a 'teoria forte' dominante do capitalismo que fala sobre a economia (capitalista). As autoras visam comprometer esta 'teoria fraca' em um modo reparador que "acolha surpresa, admita esperança, faça conexões, tolere coexistência e ofereça zelo pelo novo " (GIBSONGRAHAM, 2006, p. 8). Simultaneamente essa abordagem continua a absorver da crítica queer utilizada em seus trabalhos anteriores, enquanto elas tentam instigar uma 'desindentificação coletiva' com o capitalismo, de um modo muito similar aos quais os teóricos queer tentaram desestabilizar normativas sexuais e de relações de gênero. Elas propõem que:

ao ordenar os muitos meios que a riqueza social é produzida, transacionada e distribuída por meios outros do que os tradicionalmente associados com o capitalismo, o não capitalismo torna-se uma

\section{Gavin Brown}


multiplicidade positiva ao invés de uma negatividade vazia, e capital-ismo torna-se apenas um conjunto particular de relações econômicas situado em um vasto mar de atividade econômica (GIBSON-GRAHAM, 2006, p. 70. ênfase no original).

Isto sugere uma economia diversificada em que as transações, relações trabalhistas e empreendimentos capitalistas que constituem o que é percebido como a 'economia principal' é considerada juntamente com todas as outras transações, empreendimentos e relações econômicas que "asseguram a sobrevivência material e bem-estar" (GIBSON-GRAHAM, 2005. p. 12). Logo, além de pensar em transações econômicas em mercados convencionais, Gibson-Graham (2006, p. 71) identificam uma série de mercados alternativos - tais como aqueles com características distintivas que são frequentemente ignorados nas discussões sobre 'a economia' (por ex. mercados de produtos éticos que visam 'comércio justo', sistemas de trocas locais, mercados informais e escambo) - bem como transações econômicas que ocorrem fora dos mercados (por exemplo fluxo doméstico, reservas estatais, roubo, caça e coleta).

É importante lembrar que os mercados não podem controlar o que flui através deles - as mercadorias trocadas através destes mercados podem ser produto de inúmeras práticas e relações sociais de produção não capitalistas (incluindo escravidão, e várias formas independentes, comunitárias ou coletivas de produção). Capitalismo coexiste com muitas outras formações econômicas (GIBSON-GRAHAM, 1996). Se esquecemos disso, sustentamos o capitalismo como um monólito.

Em paralelo com o trabalho assalariado, GibsonGraham (2006) identificam formas alternativas de trabalho remunerado (incluindo o trabalho autônomo, trabalhar para a assistência social, trabalho temporário e formas de trabalho cooperativas), bem como trabalho não remunerado (na forma de trabalho doméstico, voluntariado, trabalho subsistência e escravidão). Isto continua uma tendência de seu trabalho prévio (GIBSON-GRAHAM, 1996), que teorizaram o lar como um local de múltiplas práticas não capitalistas que corporificam identidades econômicas não capitalistas.

Tendo identificado o leque de relações de trabalho e formas de transações econômicas existentes, GibsonGraham (2006) também consideram a gama de diferentes formas de empreendimentos que podem ser encontrados dentro e em paralelo com o capitalismo contemporâneo. Nesse sentido, além dos empreendimentos capitalistas elas identificam as empresas estatais, firmas capitalistas 'verdes' e 'socialmente responsáveis' e os sem-fins-lucrativos, bem como uma série de empresas comunais e empreendimentos feudais que estão em formas não capitalistas.

Ao revelar a multiplicidade de práticas econômicas não capitalistas que existem atualmente em todo o mundo, Gibson-Graham esperam desestabilizar o entendimento do capitalismo como dominante, que tudo permeia e inatacável. Para elas, uma vez que as atividades não capitalistas sejam percebidas como onipresentes e viáveis, há potencial para expandir seu alcance no aqui e agora e para transformar as economias locais (GIBSON-GRAHAM, 2006).

\section{$\mathrm{Na}$ economia diversificada, os relacionamentos são contingentes ao invés de determinados; o valor econômico é liberalmente distribuído, não estando atrelado a certas atividades e negado a outras; as dinâmicas econômicas proliferam, não restritas a um número definido de lógicas e leis reguladoras; e múltiplas temporalidades e histórias são desprendidas de uma narrativa linear (GIBSON- GRAHAM, 2005, p. 13).}

Através de uma série de projetos de pesquisa participante de longo prazo nos 'cinturões da ferrugem' da Austrália e da Nova Inglaterra, bem como nas áreas rurais das Filipinas, Gibson-Graham e seus colaboradores tentaram esboçar a diversidade de práticas econômicas e relações que operam naquelas localidades. Dentro de seus estudos de caso, GibsonGraham (2005, p. 16) foram particularmente argutas em identificar expressões de "economia comunitária" esses locais e práticas econômicas que sustentam diretamente o bem-estar e distribuem o excedente de maneira que ofereçam sustentabilidade material e cultural para comunidade, sem recorrer aos circuitos de distribuição da produção e troca capitalista.

As análises de Gibson-Graham da economia diversificada têm sido bastante criticadas por serem por demais forjadas através de um viés emancipatório, advogando novas formas de justiça social póscapitalista, sem parar para reconhecer ou analisar os meios pelos quais o poder continua a ser exercido nos espaços de 'economia comunitária' (KELLY, 2005). Elas foram acusadas de não atentarem as formas em que as relações de poder baseadas em gênero, sexualidade, etnia e religião fluem através desses espaços e práticas de economia 'alternativa' (LAWSON, 2005.

Estas críticas têm algum mérito, mas parecem

\section{Gavin Brown}


originar-se da confusão entre duas concepções da economia comunitária. Primeiro, como uma ferramenta linguística para reler uma economia; e, segundo, como um projeto ético imaginado de interdependência. Enquanto alguns estudiosos críticos podem celebrar o potencial libertador de certas formas de comunas, de trabalho não capitalista e de troca, para aqueles que vivem diuturnamente nessas relações, esses espaços podem parecer contestados, até irrelevantes (KELLY, 2005) - dificilmente considerados um bem.

Gibson-Graham reconhecem os aspectos negativos do comunal. Elas não estão tentando propor novas estruturas normativas, mas abrir espaço para a experimentação. Neste processo, aspirações, desejos, prazeres e sistemas de crenças devem ser levados em consideração juntamente com uma análise das relações econômicas (LAWRIE, 2005, p. 32). É produtivo perguntar não somente "que necessidades são supridas e que interesses atendidos por esta transação?” Mas, também, "qual o sentido pode se oferecer para todos os envolvidos?" (no processo de tentar abandonar o sentimento de impotência e melancolia). Na seção seguinte, vou começar a colocar essas questões, enquanto esboço distintas expressões de diversificadas economias gays que possam descentrar o papel da cena comercial gay da vida econômica de lésbicas e gays urbanos e, consequentemente, tornar o alcance da 'homonormatividade' menos disseminado.

\section{Práticas econômicas gays diversificadas}

Se, como já apontei, Gibson-Graham (1996) questionam como a globalização capitalista sobredetermina a emergência de diversos processos de classe não capitalistas (dificultando as tentativas de encontrar causalidade simples e singular e voltando a atenção para as intersecções produtivas de múltiplos processos), pode a mesma questão ser feita sobre o papel da homonormatividade neoliberal em sobredeterminar o surgimento de um leque de práticas econômicas e identidades não capitalistas dentro (e potencialmente excedendo aos limites de) comunidades urbanas de lésbicas e gays?

Ao explorar estas questões, Gibson-Graham (2006) recomendam que é mais prático começar com a economia diversificada, como ela ocorre em uma dada área, utilizando empreendimentos existentes, mercados e relações como recursos problemáticos e contraditórios nos quais se engaja em projetos 'de se tornar' ou que possam 'construir' algo mais desejável no futuro. Nestes termos, eu quero pensar sobre as diversas economias da vida gay e lésbica para explorar o potencial existente para a construção de relações póscapitalistas queer no momento presente. Eu não estou procurando por um espaço queer 'autêntico, não cúmplice'. Mas procuro explorar a difusão incompleta de homonormatividade neoliberal na vida cotidiana de lésbicas, gays e queers e na natureza contraditória e interdependente dos espaços que muitos homens e mulheres gays utilizam diariamente.

$\mathrm{Na}$ sequência, eu ofereço um inventário preliminar da diversidade existente de práticas econômicas gays, relacionamentos e empreendimentos (em Londres e outros lugares que conheço bem). Isto é concebido como um ato performativo de nomear diversas práticas econômicas, onde elas possam não serem normalmente encontradas. $\mathrm{O}$ ato de inventariação é um ato de inventar - destacando o potencial criativo de conceber diferentemente atos e espaços costumeiramente não nos apercebemos, constituindo um mundo que previamente não foi reconhecido. Para oferecer um pouco de clareza a este processo, eu tenho, em grande parte, atentado às categorizações oferecidas por Gibson-Graham (2006) e mantido, por exemplo, uma distinção analítica entre os mercados principais e alternativos, bem como entre trabalho assalariado e formas alternativas de remuneração.

Como elas (GIBSON-GRAHAM, 2006, p 217, nota 40), reconheço que esse processo de queerização capitalista é incompleto, e que, se a sua manobra queer fosse levada adiante, "a 'economia capitalista' desapareceria como uma categoria unificada".

Começo com o que é facilmente reconhecido (e ainda assim frequentemente negligenciado) sobre a vida econômica de lésbicas e homens gays nas metrópoles do Norte Global. A maioria dos homens gays e lésbicas urbanos se engajam em alguma forma de trabalho assalariado. A maioria dos bens e serviços que eles compram é vendida através de relações capitalistas de mercado. A maioria dos negócios que constituem o núcleo da cena comercial gay - não somente bares, discotecas e restaurantes, mas lojas de varejo voltadas ao público gay, bem como profissionais especializadas (como advogados, contadores e planejadores de casamento) - a maioria (mas não necessariamente) opera como empreendimentos capitalistas. No entanto, na cena comercial gay e em seu entorno existem vários mercados 'undergrounds' - nem todos relacionados com tráfico de drogas e prostituição (que também podem ser capitalista em suas formas).

Mas esses locais, práticas e relações não esgotam o tema. Existem muitos locais de socialização de gays e lésbicas que existem longe (ou em paralelo) da cena comercial gay - grupos sociais e de apoio, organizações religiosas e clubes desportivos, para citar somente alguns. Eles formam a espinha dorsal de um conjunto mais diversificado de práticas gays

\section{Gavin Brown}


econômicas, sociais e culturais (ANDRUCKI \& ELDER).

Da mesma forma, muitos gays e lésbicas de Londres recebem ajuda estatal, na forma de benefícios sociais - como auxílio-doença para pessoas com HIV/AIDS, bolsas por filhos ou pensões estatais. Reconhecer esses aspectos mais amplos da vida econômica de gays e lésbicas (BADGETT, 2001; BASSI, 2006; GLUCKMAN \& REED, 1997) imediatamente eleva o debate para além do foco único sobre a sexualidade, passando a considerar a interseccionalidade da sexualidade com idade, classe, (d)eficiência, etnia e gênero. Além disso, no contexto de ataques neoliberais sobre a prestação do Estado e da privatização dos serviços (em particular no atual período de austeridade), é importante considerar como estes benefícios sociais estão sendo reconfigurados, quais condicionalidades estão embutidas, e como eles podem ser defendidos.

O restante desta discussão das diversas economias gays concentra-se em três áreas diferentes da vida gay, para considerar como elas podem não ser tão diretamente parte da 'economia capitalista' como usualmente se pensa. Eu começo por identificar vários empreendimentos que são fundamentais para a vida de muitas lésbicas e homens gays em Londres, mas que não operam em uma base com fins lucrativos no âmbito de mercados (quando apropriado, eu nomeio as organizações no texto para oferecer um contexto fundamentado em meu inventário). Então eu examino uma variedade de locais e eventos, buscando determinar se eles constituem, ou não, uma forma de 'comuna' gay (ou queer). A minha análise das diversas economias gays então é concluída de um modo mais especulativo, tomando a figura do 'abastado consumidor gay' e considero como ele poderia tornarse diferente de si mesmo (e da maioria dos debates acadêmicos críticos do seu papel na promoção dos valores homonormativos) ao examinar seus arranjos domésticos e envolvimento comunitários para revelar as práticas econômicas em que ele está envolvido e que excedem as fronteiras de transações de mercado.

\section{Empreendimentos e transações gays alternativas}

No contexto de Londres, é relativamente fácil compilar uma longa lista de empresas estatais atendendo as comunidades de gays e lésbicas da capital, como especialistas em HIV e clínicas de saúde sexual e centros de tratamento, ou grupos de jovens LGBT (lésbicas, gays, bissexuais e transgêneros / transexuais) subsidiados pelas assembleias locais. Da mesma forma, há uma série organizações sem fins lucrativos (alguns deles grandes e 'corporativos', outros menores, mais amadores e populares) que prestam serviços de saúde para gays e lésbicas (HEALY, 2008). Novamente, nesta categoria, prestadoras de serviços para HIV e AIDS (por exemplo, Terence Higgins Trust), centros de aconselhamento e terapia (por exemplo, Kairos in Soho, or London Friend), instituições de caridade que organizam a assistência social para adolescentes gays (The Albert Kennedy Trust), ou grupos de apoio para idosos LGBT.

Pensando um pouco, é fácil chegar a uma lista de empreendimentos alternativos gays que tentam operar de um modo ético e socialmente responsável. Penso em um número de cafés que são de propriedade cooperativa $^{3}$ (e em grande parte dirigido por gays e/ou servindo clientela predominantemente gay), diversas moradias cooperativas e pelo menos uma casa noturna que opera sem visar lucros e depende do coletivo, como a colaboração do tipo 'faça-você-mesmo' de seus frequentadores que se voluntariam como DJs e outras funções (por exemplo, Clube Wotever, ou a antiga Homocrime). Estes empreendimentos distribuem seus excedentes econômicos para os seus membros, com base em um compromisso ético de reciprocidade e horizontalidade. Todos estes espaços existem em relações contraditórias com práticas sociais neoliberais e homonormativas.

Eu questiono o que aconteceria se, ao invés de criticar a libra 'rosa' e o dólar 'rosa', os acadêmicos gays participassem do fomento de redes de moedas alternativas 'rosas', esquemas LETS (Sistema de Troca Local) e cooperativas de crédito. Estas experiências podem construir comunidades em novos termos e permitir que os participantes possam suprir suas necessidades sem depender de pagamentos em moeda corrente, ao mesmo tempo, reconhecer que eles possuem habilidades com um 'valor de troca'.

Estas atividades têm o potencial para começar a adesão a novas formas de comunidade e pertencimento entre aqueles que se encontram excluídos da cena principal gay, como resultado de desvantagem econômica, racismo, preconceito de idade, ou falta de afinidade com a gama de identidades que são normativamente produzidas através desses locais.

Segundo, Spectrum (2001), o fórum consultivo local LGBT e organização de defesa em Brighton e Hove traçaram esses objetivos como parte da vertente econômica da sua estratégia de desenvolvimento da comunidade. De acordo com a minha preocupação para questões de interdependência entre gays e lésbicas e as redes mais amplas da comunidade em que eles levam suas vidas, é importante não negligenciar o já existente envolvimento de muitos gays e lésbicas em esquemas LETS e bancos de horas nas vizinhanças

\section{Gavin Brown}


onde residem. O potencial para compromissos interdependentes e partilha recíproca de recursos entre os limites de categorias de identidade é fundamental para o meu próximo exemplo.

\section{Commons Queer}

Eu já apontei como a análise de Gibson-Graham (2006) das economias diversificadas dá especial atenção aos modos como 'as economias comunitárias' e de várias formas de commons podem ser preservadas e ampliadas. Até hoje, poucos trabalhos consideraram como recursos comunitários voltados para gays e lésbicas (ou similar) podem servir como uma forma de commons. Quero sugerir que, prosseguir nesta linha de investigação e reconsiderar vários eventos e práticas gays e lésbicas como constituindo commons, pode elucidar novas formas de conceber suas práticas econômicas. Para este fim, quero considerar brevemente três conjuntos de espaços lésbicos, gays e queer que possam ser considerados nesses termos.

Primeiro, há um conjunto de espaços gays e queers que tem sido fundamental para o estudo geográfico da vida de homens gays e bissexuais (BELL, 1997), que são locais públicos apropriados para o cruising, prática pública de sexo homossexual. Literalmente, pelo menos em sua modalidade externa, o cruising frequentemente ocorre em locais comunitários (common ground) - florestas, charnecas e praias. Mas mesmo quando os praticantes de cruising se apropriam de banheiros públicos e outros espaços semipúblicos, é possível argumentar que o ato desviante repetitivo que constituem esses locais como lugares para prática de cruising também justifica reivindicá-los como um recurso comunal (communal resource) para a expressão do desejo erótico. Embora seja ingênuo afirmar que tais espaços não reproduzem todos os tipos de exclusão por idade, (d)eficiência e etnia, eles são, frequentemente, mais acessíveis a uma ampla gama de homens com desejos homoeróticos do que muitos clubes de sexo e saunas, onde o custo de admissão pode servir para excluir os homens de baixo poder aquisitivo. Cada vez mais, esses locais precisam ser defendidos contra mudanças de políticas de policiamento do espaço público e privatização do desejo.

Em segundo lugar, tem havido, recentemente, um aumento de interesse acadêmico em uma série de eventos e espaços que, frequentemente, se autoidentificam como 'queer' no lugar de LGBT, e que tentam em forma e função oferecer algo diferente da indústria hegemônica de lazer gay. Estes eventos, encontros e santuários que são de baixo custo (ou nenhum), organizados do modo 'faça-você-mesmo', onde a distinção entre produtores e consumidores não é tão marcada. Frequentemente, esses eventos ocorrem em terras de propriedade coletiva, em centros comunitários, ou em espaços ocupados. Estou pensando aqui, em particular, em Queeruption (BROWN, 2007a; 2007b; VANELSLANDER, 2007), encontro internacional (mais ou menos) anual de ativistas anarco-queers, onde é criado um espaço temporário autônomo, dentro do qual os participantes podem compartilhar habilidades e redes de contato que inspirem ainda mais experimentações autônomas nas respectivas comunidades de origem. Na mesma linha, também se poderia pensar sobre a proliferação de festivais Ladyfest, que celebram a produção musical amadora e a criatividade das mulheres (SPENCER, 2005), ou santuários Radical Faerie, onde homens gays se reúnem para celebrar e experimentar sua espiritualidade (ANDRUCKI \& ELDER, 2007; HERRING, 2007). A partilha e a dádiva de competências, afetos e conhecimentos são fundamentais para todos estes locais, uma vez que buscam, conscientemente, oferecer uma alternativa mais coletiva e comunitária à vida urbana gay e prefiguram modos de vida pós-capitalistas.

Em terceiro lugar, quero refletir se é possível repensar em algumas das principais instituições das comunidades locais de gays e lésbicas como commons culturais. Existem várias - pequenas, independentes e muitas vezes informais - organizações comunitárias que não (necessariamente) foram incorporadas grupos religiosos (por exemplo, Imaan ou Quaker Quest), clubes desportivos (por exemplo, Irons gay golfing), organizações de base militante (por exemplo, Queers Without Borders), clubes do livro e grupos sociais e de apoio. Eles, tanto quanto bares e clubes gays, são a espinha dorsal das redes sociais gays e lésbicas. Para aqueles que são excluídos ou estranhos à cena comercial, esses grupos ou redes podem ser ainda mais importante.

Embora tenha se tornado moda para ativistas queer radicais e estudiosos ridicularizarem as Paradas do Orgulho Gay como o cúmulo de tudo o que está errado com a vida gay 'homonormativa' contemporânea, especialmente agora que os maiores desses eventos atrai patrocínio corporativo significativo, elas permanecem festividades culturais e políticas importantes, que são apreciadas por muitos, tanto dentro quanto fora das comunidades gays e lésbicas visíveis. Estes são certamente bons exemplos dos 'espaços cúmplices' sobre os quais Oswin (2005) escreve. Mas, como tais, eles servem a muitos propósitos para os seus diversos membros. Enquanto as Paradas do Orgulho Gay, em grande parte do Norte Global, podem não ser mais os locais de resistência

\section{Gavin Brown}


que eram há vinte e cinco ou trinta anos atrás, elas ainda são expressões politicamente importantes de visibilidade pública, que buscam desafiar o conservadorismo social e moral dominante (especialmente, atualmente, em grande parte da Europa Central e leste europeu e os países do Sul Global). Eu acredito que é possível abordar as Paradas de Orgulho como commons, através dos quais há um livre compartilhar de conhecimento dos diversos jeitos de se fazer 'gay', uma doação de glamour e brilho que reencanta as ruas da cidade, para a fruição de uma plateia de todas as categorias sexuais de identidade.

\section{0 abastado consumidor gay}

Eu encerro minhas considerações sobre as diversas economias urbanas da vida gay, analisando a figura do consumidor gay. Faço-o, a fim de contemplar como ele poderia ser diferente de si mesmo, ao revelar práticas econômicas cuja participação levam ao descentramento de sua vida do consumo hedonista da cena comercial gay. Nas representações (tanto acadêmica quanto jornalísticas) da vida urbana gay, o consumidor gay é, invariavelmente, um homem (estes debates reconhecem as diferenças de gênero nos níveis de renda entre homens e mulheres) que se pressupõe branco (embora isso raramente seja diretamente marcado), bastante instruído e com um bom emprego. Ele vive na parte central da cidade, provavelmente em um loft minimalista, que é decorado (em grande parte) em um estilo normativamente 'masculino'. Ele está bem vestido e arrumado - o cúmulo da metrossexualidade (SIMPSON, 2002). Grande parte de sua vida social é passada em bares gays, clubes e restaurantes. Ele prefere negócios e serviços geridos por gays (ou pelo menos aqueles que são reconhecidos nos meios gays como sendo 'amigável aos gays' [gayfriendly]). Todas as suas escolhas de consumo confirmam a sua identidade como um homem urbano gay. Ele tem um parceiro em um relacionamento longo, mas eles têm uma relação aberta, que permite a cada um deles terem encontros sexuais casuais, dentro de parâmetros cuidadosamente negociados. Ele é, naturalmente, um estereótipo (e eu reconheço que, por esse fazer estereótipo constar aqui, corro o risco de reforçar a própria figura que viso descentralizar).

Mas e se olharmos um pouco mais entre as lacunas nessa representação estereotipada? Seria possível encontrarmos práticas, dentro desses espaços, que contribuam para diversificar economias para além do trabalho assalariado, dos empreendimentos capitalistas e das transações do mercado? Facilmente, notamos que este homem compra mercadorias em mercados undergrounds, toda vez que compra drogas para se divertir na noite. Ao escolher apoiar o "amigável aos gays" nas empresas, ele está fazendo uma escolha ética ao gastar com empresas que, ao menos em um aspecto, são 'socialmente responsáveis' (mesmo que paguem aos seus funcionários um salário de subsistência, não contratem sindicalizados ou não considerem seu impacto ambiental). Podemos revelar mais da diversidade de suas práticas econômicas, olhando para os seus arranjos domésticos.

Os usos dos homens gays de suas casas, os significados que atribuem a eles e os aspectos cotidianos de suas vidas, até recentemente, foram ignorados pelos geógrafos das sexualidades (GORMAN-MURRAY, 2006; 2007; WAITT \& GORMAN-MURRAY, 2007). Como resultado, o papel desta forma de 'trabalho' doméstico para sustentar famílias gays e redes sociais é subreconhecido. Mas vamos pensar sobre isso. A maioria dos homens gays (mesmo os estereotipados consumidores gays abastados) ainda limpam suas próprias casas, lavam suas próprias roupas, e cozinham, pelo menos algumas das suas próprias refeições. Este trabalho não remunerado, como muitas feministas reconheceram, tem valor econômico real que é negligenciado nos cálculos do PIB. É também uma forma de 'trabalho' que existe fora das relações de mercado, mas também pode ser fortemente imbuída de uma ética de cuidado e pode gerar sentimentos de satisfação e afeição juntamente com outras respostas afetivas.

Um grande número de estudiosos (ROSENEIL, 2007; WEEKS, 2007; WEEKS et al, 2001) descreveram os padrões de domesticidade, amizade e intimidade que antes eram, predominantemente, encontrados entre lésbicas e gays, mas que estão cada vez mais sendo reproduzidos entre camadas mais amplas da sociedade, assim como os padrões de monogamia tornam-se mais usuais. Estas escolhas domésticas e íntimas não necessariamente posicionam o casal monogâmico como primário; elas priorizam as amizades de longo prazo sobre (potenciais) amantes de curto prazo, reconhecem que romance e intimidade sexual não são obrigatoriamente combinados, e frequentemente integram ex-amantes na rede de amigos (de fato, podem não estar claras as fronteiras entre amigos e amantes, sendo objetos de renegociação). Por quais práticas econômicas diversificadas essas teias complexas, mutáveis, de amigos e amantes são sustentadas? O que é doado, compartilhado ou transacionado nesses relacionamentos? Como a dinâmica de gerações ou entre classes inspira ou complica a partilha de conhecimentos, a doação ou empréstimo de dinheiro ou expressões de carinho?

Para retornar, mais uma vez, com o estereótipo do

Gavin Brown 
consumidor gay abastado, não está fora do campo de possibilidades, acreditar que ele também se envolve em uma série de outras atividades que são ignoradas na recorrente descrição de uma vida focada em locais de consumo gay. Por exemplo, poderíamos acreditar que ele participa de uma horta comunitária e regularmente compra sua carne e produtos lácteos na feira, diretamente dos produtores, escolhendo conscientemente, por razões éticas, apoiar a produção local de alimentos orgânicos. Ele arruma tempo para frequentar as reuniões trimestrais do fórum local LGBT, ajudando a moldar o calendário de eventos realizados durante o 'mês da História LGBT' e as festividades do 'orgulho' da cidade, bem como pode fazer um elo com a polícia em torno de questões de segurança da comunidade, assegurando que as 'Câmaras de Comércios' locais operem de forma não discriminatória.

Os exemplos enumerados ainda implicam um alto grau de privilégio social e econômico. E eu não estou procurando negar a riqueza dessa figura hegemônica gay (ou invalidar as experiências de homens menos privilegiados), mas, simplesmente, lançar uma luz diferente sobre suas escolhas de consumo e as formas com que ele contribui para comunidades interdependentes. Esta gama de atividades dissolve a centralidade do consumo nos mercados tradicionais e a economia doméstica privatizada da vida do profissional, urbano, gay estereotipado que tem sido vilipendiado como sendo a vanguarda da reprodução da homonormatividade, 'a política sexual do neoliberalismo'.

Assim, podemos argumentar que, juntamente com sua estereotipada fruição dos locais de consumo 'gay, há uma gama mais ampla de diversas práticas econômicas, que incluem elementos de autoabastecimento; voluntariado e outras formas de engajamento comunitário (o apoio ao comércio ético que reconfigura as relações com ambientes não humano) e a partilha mútua de informações e conhecimentos que estimulam a solidariedade comunal.

\section{Observações finais}

Neste artigo realizei uma crítica às teorias 'fortes' da homonormatividade, que apresentam a vida urbana gay, no Norte Global, como sendo inteiramente saturada pela mercadoria e estruturalmente moldada pelo neoliberalismo, fazendo ambos parecerem dominantes, completos e inatacáveis. Parafraseando Gibson-Graham (1999), eu questionei a violência cometida por estudiosos 'queer' críticos, quando eles normalizaram toda a vida gay contemporânea como sendo a vida gay homonormativa, que é ditada pelos imperativos políticos e econômicos do neoliberalismo.

Dentre os engajamentos recentes dos geógrafos com os debates em torno da 'homonormatividade', eu aprecio o apelo de Oswin (2005) para transcendermos oposições binárias - entre vida gay homonormativa e oposição transgressora queer - reconhecendo a cumplicidade de todos os espaços gays na reprodução de uma gama de práticas normativas (não limitadas àquelas diretamente relacionadas com normas sexuais). Entretanto, eu sugeri que, na tentativa de performativamente deslocar a centralidade da homonormatividade na vida gay, pode ser mais produtivo pensar nas complexas relações que existem através de categorias 'normativas' de identidade como sendo moldadas pela interdependência ao invés de cumplicidade.

Partindo da avaliação de Gibson-Graham (2005, 2006), a tentativa de elaborar economias diversas que descentrem o capitalismo da vida contemporânea e abrir um espaço no qual práticas econômicas e relações não capitalista possam ser entendidas como uma multiplicidade de potencialidades positivas, ao invés de uma ausência, tendo eu buscado esboçar as diversas economias da vida urbana gay. Neste esforço preliminar, eu observei uma série de práticas econômicas e relações dentro da vida gay contemporânea que existem em paralelo àqueles locais de consumo considerados fundamentais para a produção de relações sociais homonormativas. Para este fỉm, tenho notado a importância das atribuições do Estado de bem-estar social nas vidas de muitas lésbicas e homens gays. Eu apontei para a existência de uma gama de empreendimentos alternativos, 'éticos' e 'sem fins lucrativos' que existem ao lado dos negócios - mais visíveis e com fins lucrativos - que constituem o cenário comercial gay.

Além disso eu questionei se alguns dos eventos e espaços centrais da vida gay, como Paradas do Orgulho e locais de cruising, podem, na verdade, constituir 'commons queer', que são recursos comunitários onde habilidades, conhecimentos e intimidade podem ser livremente compartilhados de um modo recíproco e comunal. E, no espírito performativo do trabalho de Gibson-Graham sobre economias diversas, eu ofereci uma perspectiva alternativa da vida do consumidor, branco, abastado e gay, procurando revelar as práticas econômicas alternativas e respostas éticas interdependentes que ele possa, quiçá, se engajar, visando com isso, tornar este estereótipo 'diferente de si mesmo'.

Gostaria de concluir, sugerindo que a abordagem das economias diversificadas oferece possibilidades para o desenvolvimento de estratégias de pesquisa, que

\section{Gavin Brown}


possam se engajar com toda a gama de práticas e relações econômicas em que lésbicas e gays participam, em qualquer dada localidade. Para seguir esta abordagem, é necessário que levem a geografia sexual em novas direções metodológicas e o engajamento em pesquisa participativa com pessoas queer, identificando necessidades e desejos insatisfeitos em suas vidas, e as habilidades e recursos subutilizados que têm à sua disposição e podem ser usados para os satisfazerem. Ao fazer isso, talvez tenhamos que mudar o foco dos estudos geográficos da (homo)sexualidade da cena comercial gay para espaços domésticos, grupos sociais informais e a multitude de outras atividades econômicas e espaços que lésbicas e se engajam.

Nesse processo, podemos descobrir que homonormatividade começa parecer menos abarcadora; que as vidas de lésbicas e homens gays parecem um pouco menos saturadas de mercadorias e que o estereótipo do abastado, branco, consumidor gay começa a se dissolver quando nós nos engajamos com todas as contradições, cumplicidades $\mathrm{e}$ interdependências que marcam vidas de lésbicas e gays. Espero que a ética performativa de trazer a existência, que é central para a abordagem de economias diversas, continuará a valorizar as, negligenciadas, práticas e relações não capitalistas da vida gay.

Finalmente, acredito que essa abordagem pode oferecer novas possibilidades para estudar e intervir na vida gay fora dos centros metropolitanos do Norte Global. Muito frequentemente, as geografias das sexualidades focaram nesses locais, produziram um modo de investigação que 'mede' outros locais e outras vidas em comparação com o desenvolvimento do cenário comercial gays do Norte Global, ou a partir do modelo transatlântico de cidadania e identidade sexual (e na maior parte das vezes, encontra-os ausentes).

Agradecimentos: Gostaria de agradecer a Kathy Gibson, Nina Laurie e Diane Richardson, entre outros, por sua perspicácia e instigantes comentários sobre versões anteriores deste trabalho que foram apresentadas na Conferência AAG 2007, em São Francisco e do ESRC Seminário de economias póscoloniais da Universidade de Newcastle.

1 Tradução: Rafael Mendonça de Paula.
2 Neoliberalismo é um termo altamente contestado (HARVEY, 2005; LEITNER et al, 2007; SMITH \& ROCHOVSKA, 2007). Muito frequentemente, esse conjunto de práticas políticas econômicas, que incrementa de direitos de propriedade privatizadas, mercados livres e comércio livre, é tomado como um sinédoque do capitalismo. Isso encobre a diversidade das diferentes práticas circunscritas pelas ideologias neoliberais, e pelos diversos modos específicos nos quais elas desenvolveram histórica e geograficamente.

3 Fiquei intrigado ao descobrir, enquanto escrevia esse artigo, que entre os diversos usos da bandeira arco-íris, além da sua onipresença como símbolo do Orgulho LGBT, foi adotada como a bandeira do cooperativismo internacional durante boa parte do século XX.

\section{Referências}

ANDRUCKI, Max; ELDER, Glen. Locating the state in queer space: GLBT non-profit organizations in Vermont, USA. Social and Cultural Geography, v. 8, n. 1, p. $89-104,2007$.

BADGETT, Mary Virginia Lee. Money, Myths and Change: The Economic Lives of Lesbians and Gay Men. Chicago: University of Chicago Press, 2001.

BASSI, Camila. Riding the dialectical waves of gay political economy: a story from Birmingham's commercial gay scene. Antipode, n. 38, n. 2, p. $213-$ 235, 2006.

BELL, David. One-handed geographies: an archaeology of public sex. In: BOUTHILLETTE, Anne-Marie; RETTER, Yolanda. Queers in Space: Communities/Public Places/Sites of Resistance. Port Townsend,WA: Bay Press, 1997, p. $81-87$.

BELL, David; BINNIE, Jon. The Sexual Citizen: Queer Politics and Beyond. Cambridge: Polity Press, 2000.

BELL, David; BINNIE, Jon; Cream, Julia; Valentine Gill. All hyped up and no place to go. Gender, Place and Culture, v. 1, n. 1, p. $31-47,1994$.

BROWN, Gavin. Mutinous eruptions: autonomous spaces of radical queer activism. Environment and Planning A, v. 39, n. 11, p. 2685 - 2698, 2007a.

BROWN, Gavin. Autonomy, affinity and play in the

Gavin Brown 
spaces of radical queer activism. In: BROWNE, Kath; LIM, Jason; BROWN, Gavin. Geographies of Sexualities: Theory, Practices and Politics. Aldershot, Hants: Ashgate, 2007b, p. 195 - 206.

BROWN, Gavin. Urban (homo)sexualities: ordinary cities and ordinary sexualities. Geography Compass, v. 2 , n. 4 , p. 1215 - 1231, 2008,

BROWNE, Kath; LIM, Jason; BROWN, Gavin. Geographies of Sexualities: Theory, Practices and Politics. Aldershot, Hants: Ashgate, 2007.

CASEY, Mark. The queer unwanted and their undesirable 'otherness'. In: BROWNE, Kath; LIM, Jason; BROWN, Gavin. Geographies of Sexualities: Theory, Practices and Politics. Aldershot, Hants: Ashgate, 2007, p 125 - 136.

CHASIN, Alexandra. Selling Out: The Gay and Lesbian Movement Goes to Market. New York: Palgrave Macmillan, 2000.

DUGGAN, Lisa. The new homonormativity: the sexual politics of neoliberalism. In: CASTRONOVO, Russ; NELSON, Dana. Materialising Democracy: Towards a Revitalized Cultural Politics. Durham, NC: Duke University Press, 2002, p. 175 - 194.

ELDER, Glen. Response to 'Queer patriarchies, queer racisms, international'. Antipode, v. 34, n. 5, p. $987-$ 991, 2002.

ENG, David; HALBERSTAM, Judith; MUÑOZ, José Esteban. What's queer about queer studies now? Social Text, v. 23, n. 3 - 4, p. $1-17,2005$.

GRAHAM, Julie; GIBSON, Katherine. The End of Capitalism (As We Knew It): A Feminist Critique of Political Economy. Oxford: Blackwell, 1996.

GRAHAM, Julie; GIBSON, Katherine. Queer(y)ing capitalism in and out of the classroom. Journal of Geography in Higher Education, v. 23, n. 1, p. 80 85, 1999.

GRAHAM, Julie; GIBSON, Katherine. Surplus possibilities: postdevelopment and community economics. Singapore Journal of Tropical Geography, v. 26, n. 1, p. 4 - 26, 2005.

GRAHAM, Julie; GIBSON, Katherine. A Postcapitalist Politics. Minneapolis, MN: University of Minnesota Press, 2006
GLUCKMAN, Ammy; REED, Betsy (Eds). Homo Economics: Capitalism, Community and Lesbian and Gay Life. New York: Routledge, 1997.

GORMAN-MURRAY, Andrew. Homeboys: uses of home by Australian gay men. Social and Cultural Geography, v. 7, n. 1, p. $53-69,2006$.

GORMAN-MURRAY, Andrew. Contesting domestic ideals: queering the Australian home. Australian Geographer, v. 38, p. $195-213,2007$.

HARITAWORN, Jin. Queer mixed race? Interrogating homonormativity through Thai interraciality. In: BROWNE, Kath; LIM, Jason; BROWN, Gavin. Geographies of Sexualities: Theory, Practices and Politics. Aldershot, Hants: Ashgate, 2007, p. 101 112.

HARVEY, David. A Brief History of Neoliberalism. Oxford: Oxford University Press, 2005.

HEALY, Stephen. Caring for ethics and the politics of health care reform in the United States. Gender, Place and Culture, v. 15, n.3, p. 267 - 284, 2008.

HERRING, Scott. Out of the closets, into the woods: RFD, Country Women, and the Post-Stonewall emergence of queer anti-urbanism. American Quarterly, v. 59, n. 2, p. 341 - 372, 2007.

HUBBARD, Phil. Between transgression and complicity (or: can the straight guy have a queer eye?)'. In: BROWNE, Kath; LIM, Jason; BROWN, Gavin. Geographies of Sexualities: Theory, Practices and Politics. Aldershot, Hants: Ashgate, 2007, p. 151 156.

HUBBARD, Phil. Here, there, everywhere: the ubiquitous geographies of heteronormativity. Geography Compass, v. 2, n. 3, p. 640 - 658, 2008.

KELLY, Phillip. Scale, power and the limits to possibilities. Singapore Journal of Tropical Geography, v. 26, n. 1, p. $39-43,2005$.

LAURIE, Nina. Putting the messiness back in: towards a geography of development as creativity. Singapore Journal of Tropical Geography, v. 26, n. 1, p. $32-$ $35,2005$.

LAWSON, Victoria. Hopeful geographies: imagining ethical alternatives. Singapore Journal of Tropical

\section{Gavin Brown}


Geography, v. 26, n. 1, p. 36 - 38, 2005.

LEITNER, Helga; PECK, Jamie; SHEPPARD, Eric (Eds). Contesting Neoliberalism: Urban Frontiers. London: Guilford Press, 2007.

LIM, Jason. Queer critique and the politics of affect. In: BROWNE, Kath; LIM, Jason; BROWN, Gavin. Geographies of Sexualities: Theory, Practices and Politics. Aldershot, Hants: Ashgate, 2007, p. 53 - 68.

NAST, Heidi. Queer patriarchies, queer racisms, international. Antipode, v. 34, n. 5, p. 877 - 909, 2002.

OSWIN, Natalie. Towards radical geographies of complicit queer futures. ACME: An International ejournal for Critical Geographies, v. 3, n. 2, p. 79 86,2005

OSWIN, Natalie. The end of queer (as we knew it): globalization and the making of a gay-friendly South Africa. Gender, Place and Culture, v. 14, n. 1, p. 93 110, 2007.

OSWIN, Natalie. Critical geographies and the uses of sexuality: deconstructing queer space. Progress in Human Geography, v. 32, n. 1, p. 89 - 103, 2008.

PUAR, Jasbir. Mapping US homonormativities. Gender, Place and Culture, v. 13, p. 67 - 88, 2006.

PUAR, Jasbir. Terrorist Assemblages: Homonationalism in Queer Times. Durham, NC: Duke University Press, 2007.

RICHARDSON, Diane. Desiring sameness? The rise of a neoliberal politics of normalization. Antipode, v. 37 , n.3, p. $515-535,2005$.

ROSENEIL, Sasha. Queer individualization: the transformation of personal life in the early 21 st century. NORA: Nordic Journal of Women's Studies, v. 15, n. $2-3$, p. $84-99,2007$.

SEDGWICK, Eve Kosofsky. Touching, Feeling: Affect, Pedagogy, Performativity. Durham, NC: Duke University Press, 2003.

SIMPSON, Mark. Sex Terror: Erotic Adventures in Pop Culture. Binghampton, NY: Harrington Park Press, 2002.

SMITH, Adrian; ROCHOVSKA, Alena. Domesticating neo-liberalism: everyday lives and the geographies of post-socialist transformations. Geoforum, v. 38, n. 6, p. $1163-1178,2007$.

SMITH, Joe; CLARK, Nigel; YUSOFF, Kathryn. Interdependence. Geography Compass, v. 1, n. 3, p. $340-359,2007$.

SOTHERN, Matthew. (Un)queer patriarchies: or, what we think when we fuck. Antipode, v. 36, n. 2. p. $183-$ 191, 2004.

SOTHERN, Matthew. HIV+ bodyspace: AIDS and the queer politics of future negation in Aotearoa/ New Zealand. In: BROWNE, Kath; LIM, Jason; BROWN, Gavin. Geographies of Sexualities: Theory, Practices and Politics. Aldershot, Hants: Ashgate, 2007, p. $181-194$.

SPECTRUM. LGBT Community Strategy 2001 2006 Spectrum LGBT Community Forum. Brighton: Sussex, 2001.

SPENCER, Amy. DIY: The Rise of Lo-fi Culture. London: Marion Boyars, 2005.

VANELSLANDER, B. Long live temporariness: two queer examples of autonomous spaces. Affinities: A Journal of Radical Theory, v.1, n. 1, p. 5- 11, 2007. $<\mathrm{http}$ //affinitiesjournal.org/index.php/affinities/ article/viewFile/3/22>

VISSER, Gustav. The homonormalisation of white heterosexual leisure spaces in Bloemfontein, South Africa. Geoforum, v. 39, n.3, p. 1347 - 1361, 2008.

WAITT, Gordon; GORMAN-MURRAY, Andrew. Homemaking and mature age gay men 'down-under': paradox, intimacy, subjectivities, spatialities, and scale. Gender, Place and Culture, v. 14, p. 569 - 584, 2007.

WEEKS, Jeffrey. The World We Have Won. London: Routledge, 2007.

WEEKS, Jeffrey; HEAPHY, Brian; DONOVAN, Catherine. Same Sex Intimacies: Families of Choice and Other Life Experiments. London: Routledge, 2001.

Recebido em 25 de dezembro de 2011. Aceito em 26 de junho de 2012. 